\title{
Correction to: Markus Schwaiger, MD (Born 1950)
}

\author{
Frank M. Bengel, $M D^{\mathrm{a}}$ on behalf of History Corner \\ a Department of Nuclear Medicine, Hannover Medical School, Hannover, Germany
}

doi: $10.1007 / \mathrm{s} 12350-021-02798-1$

\section{CORRECTION TO: JOURNAL OF NUCLEAR CARDIOLOGY HTTPS://DOI.ORG/10.1007/S12 350-021-02765-W}

Please note that the degree information should be listed as Markus Schwaiger, MD. The title should be listed as Markus Schwaiger, MD (Born 1950). It was incorrectly listed as $\mathrm{MD}, \mathrm{PhD}$ previously.
Publisher's Note Springer Nature remains neutral with regard to jurisdictional claims in published maps and institutional affiliations.

The original article can be found online at https://doi.org/10.1007/ s12350-021-02765-w.

Reprint requests: Frank M. Bengel, MD, Department of Nuclear Medicine, Hannover Medical School, Carl-Neuberg-Str. 1, 30625

Hannover, Germany; bengel.frank@mh-hannover.de

J Nucl Cardiol 2022;29:14.

1071-3581/ $\$ 34.00$

Copyright (c) 2021 American Society of Nuclear Cardiology. 